\section{Pause for postdocs}

C

uriosity. Is that what induces highly educated people in their early thirties, many of whom have a family, to work for just over half the salary of other workers with a doctoral degree, less than a dollar an hour more than the Harvard janitor? According to a recent survey, roughly one-third of postdoctoral researchers say they are motivated by the prospect of becoming independent researchers in their own right. Rather than money, it seems that postdocs could be rendered more productive and better satisfied by a simple formal exchange to establish exactly what it is they have been recruited to do.

In October 2003 we examined the roles and rights of postdocs (Nat. Genet. 35, 109; 2003) and pointed out that a large proportion of research is carried out by postdoctoral researchers whose status, conditions and remuneration vary. We also highlighted the difficulty in establishing accurate data on the postdoctoral plight, given that many institutions do not even have an office for postdoctoral research. Now, the Sigma Xi Scientific Research Society has overcome these obstacles to produce survey of 7,600 postdoctoral researchers working in the US, the results of which are available at http://postdoc.sigmaxi.org/results/ and have been circulated with the May-June edition of American Scientist.

Although $40 \%$ are US citizens, most of whom obtained their $\mathrm{PhDs}$ in the US, 54\% hold temporary visas and are citizens of other countries, most frequently China (16\%), India (6\%) and Germany (4\%), most of whom obtained their doctorates in their countries of citizenship. The postdoctoral period is the opposite of casual work, constituting a specialized professional training step taken at a relatively advanced stage in a researcher's career. Reflecting this, $70 \%$ of postdocs in the survey were married, but for $43 \%$ of married postdocs from overseas, one spouse was not working outside the home. Visa restrictions and lack of childcare provision were cited as contributory factors.

The Sigma Xi survey found that a small increase in structured oversight or formal training correlated with increased production of high-quality papers and with postdoc satisfaction. The survey suggests that providing a written plan covering postdoc and advisor responsibilities and regular formal reviews would result in a level of satisfaction elsewhere associated with a $\$ 20,000$ salary differential. If these measures increased productivity by just $1 \%$, this could equal the amount of research publication generated by 500 new postdoctoral positions.
From the Nature Genetics perspective, a successful career is one that focuses on research quality. Therefore, a structured approach begins at the first application to the lab. As with your original choice to undertake a particular doctoral project, try to answer the following questions before proceeding. Is this the most important scientific question I can ask? How do my intellect, training and skills make me the best person to tackle it? Does my advisor's lab provide the best model system and the intellectual and material tools to address the question? In advocating this strategic pause, we acknowledge that the researcher's own skills are the primary asset with which he or she travels. Examining the demographics revealed in the survey, there also seems to be a great opportunity for other nations to implement creative funding to avail themselves of the US research infrastructure to train their postdoctoral researchers in strategic areas.

Because most postdocs surveyed are engaged in federally funded (69\%) biomedical research (74\%), many will be hired to work on a grant-funded project that has passed peer review and will be subsequently scrutinized in light of the original proposal. To the weary principal investigator, this may seem to be all the structure the project and the postdoc need. Wrong! Your newly recruited colleague brings a fresh perspective and creative thinking. This is an ideal opportunity to examine the framework in which the experiments are to be carried out and interpreted and how the field has evolved since the grant was submitted.

Choosing a productive experimental system is a decisive skill in research. It is also one of the hardest skills to teach in university courses because of the limited research experience of the students. In the research setting, even when regular literature reviews are scheduled, the narrow focus of the research group and the rapid competitive pace of research limits appreciation of work outside the immediate area. Here's one idea that might help.

Internships provided by research journals allow a $\mathrm{PhD}$ researcher to gain judgment by critically reading hundreds of manuscripts and then return to the research community with an ability to select and design research that is not limited to the specialist areas in which the postdoc and advisor have trained but cuts across several fields. This might be an efficient use of time while waiting for those fellowship applications to be approved. 